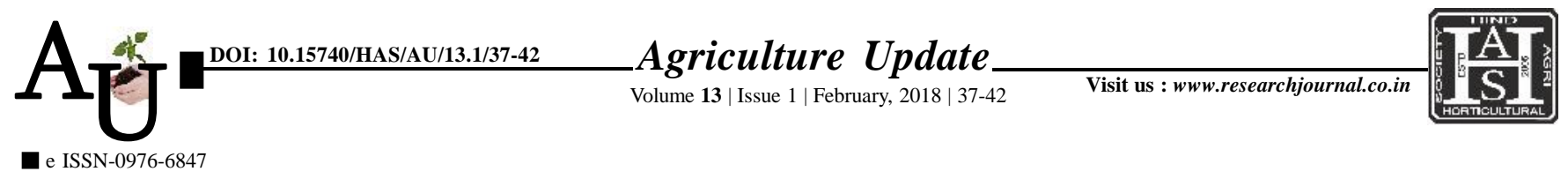

\title{
Reserach Aвticle: Socio-economic and psychological characteristics of vermicomposting farmers of Gulbarga district of Karnataka
}

\section{Shreedevi A. Sankaratti and S.N. Hanchinal}

Article Chronicle :

Received :

25.09.2017;

Revised :

13.12.2017;

Accepted :

29.12.2017

KeY Words:

Risk orientation, Scientific orientation, Vermicomposting

\section{Shreedevi A.}

Author for correspondence :

Sankaratti

Department of Agricultural Extension Education, College of

Agriculture, University of Agricultural Sciences, Dharwad (Karnataka) India

E-mail: shridevi. sankaratti@gmail.com

See end of the article for authors' affiliations
SUMMARY : The study was conducted in Gulbarga district of Karnataka during the year 2012-13. Four taluks namely Gulbarga, Jewargi, Aland and Afazalpur were purposively selected based on highest number of vermicomposting pits and from each taluk, two villages were selected and from each village, fifteen farmers were selected randomly thus the total sample comprised of 120 respondents. The expost facto research design was used for the study. The data were collected using pre-tested structured interview schedule personally. The collected data were analyzed using appropriate statistical tools. The results of the study revealed, majority of the respondents was middle aged and more number of farmers had studied upto high school, majority of the vermicompost farmers had high farming experience with small landholdings. Majority of the vermicompost farmers belonged to high annual income (> Rs. $51,000)$ and half of the farmers had regular habit of consulting neighbors and relatives as a source of information for taking operational decision for both agricultural as whole in addition to vermicomposting. High majority of the farmers regularly participated in training, krishimela and demonstration. Cent per cent of respondents were regular viewers of Television, occasional listener of radio and occasional reader of news papers. Majority of respondents belonged to medium level category of economic motivation, risk orientation, scientific orientation and market orientation.

How to cite this article : Sankaratti, Shreedevi A. and Hanchinal, S.N. (2018). Socio-economic and psychological characteristics of vermicomposting farmers of Gulbarga district of Karnataka. Agric. Update, 13(1): 37-42; DOI : 10.15740/HAS/AU/13.1/37-42. 